\title{
Mining Equipment Technical Condition Monitoring
}

\author{
Evgeny Kuzin ${ }^{2}$, Vladimir Bakin ${ }^{3}$, and Dmitriy Dubinkin ${ }^{1-2, *}$ \\ ${ }^{1}$ T.F. Gorbachev Kuzbass State Technical University, Russia, Kemerovo \\ ${ }^{2}$ Branch of T.F. Gorbachev Kuzbass State Technical University, Russia, Prokopyevsk \\ ${ }^{3}$ Mine "Taldinskaya West", "SUEK-Kuzbass", Russia, Prokopyevsk
}

\begin{abstract}
The Earth, being the main object and operational basis for mining, is exposed to the greatest impact because of extracting minerals. Protection of elements of the biosphere, including subsoil, should provide for the provision of scientifically based and economically justified completeness and complexity of use. The article discusses the need to monitor the technical condition of mining equipment, as applied to assessing its technical condition and reducing energy consumption by this equipment. The dependence of energy consumption on vibration parameters and temperature of equipment surfaces is shown. The data of the results of vibration parameters monitoring are given. Criteria are given for estimating the energy efficiency of operation of process equipment and, accordingly, the influence of these parameters on the environment.
\end{abstract}

\section{Introduction}

Ensuring safety at mining facilities is understood as a single system consisting of industrial safety, labor protection and environmental safety, one of the main tasks is the organization of an effective system for monitoring technological processes to ensure trouble-free operation of process equipment [1].

In the conditions of mining production, an objective and rapid assessment of the degree of ecological danger of a particular technological or organizational decision, the enterprise as a whole, is an urgent necessity [2].

Such an assessment is made possible by the results of a comprehensive diagnostic monitoring of machines and individual units of mining equipment using non-destructive testing methods $[6,7,8,9,10]$.

\section{Materials and Methods}

From all the variety of methods of nondestructive testing, to assess the technical condition of the equipment and its impact on the environment, vibrodiagnostics, thermal control and analysis of the parameters of lubricants, including spectro-emission analysis of oils, were

\footnotetext{
* Corresponding author: $\underline{\text { ddm.tm@ } @ \text { kuzstu.ru }}$
} 
selected. Vibro-diagnostics quite fully characterizes the technical state of the object and the dissipation of energy.

In Fig. 1. Spectra are presented for the same drive point of the belt conveyor, before and after a certain operating time.

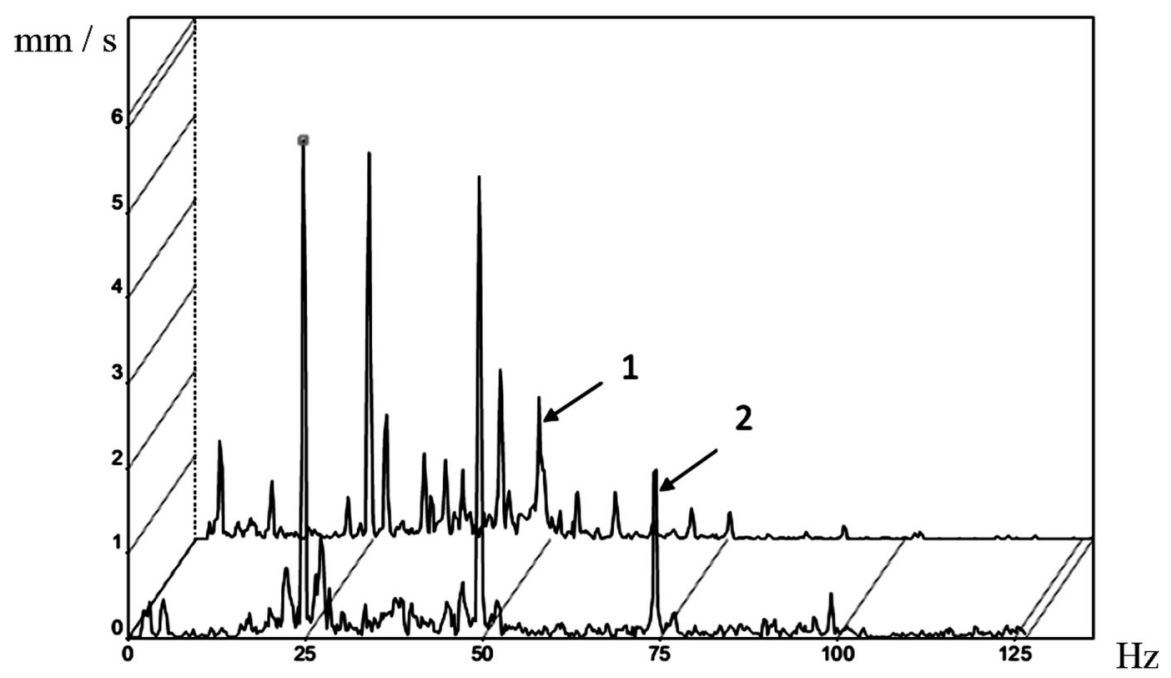

Fig. 1. Comparison of vibration spectra for the drive of a conveyor belt: 1 - date of measurement on May 14, 2014; 2 - date of measurement 10/10/2015.

Spectrum 1 (see Fig. 1) characterizes the unbalance of the primary drive shaft. This defect refers to zone $\mathrm{C}$ (a limited operational state) according to [3]. At the same time, no operational intervention was required in the drive. Spectrum 2, when the drive is used, 10770 hours does not come out of the criteria for zone C, but characterizes, in addition to imbalance, another defect called the "shaft battle". The defect of the shaft battle most often characterizes the incompatibility of the shafts caused by the defects of the coupling, or, which is much less often, defects in the shaft - wear, bending, cracking. A similar spectral pattern can be caused by a weakening of the attachment of the unit to the foundation. On this drive, as a result of visual and measurement control after the stop, it was revealed that the reactive traction of the drive was fixed to the foundation, which was caused by the previously revealed imbalance.

The vibrational signal taken from the gears fixed on the reactive thrust (without the capital base) is usually of a complex nature, it usually contains oscillations over a wide range of frequencies: vibration with excitation frequency, its harmonics and possibly subharmonics, and sometimes other frequency components [4]. However, in the present work, we are not interested in the actual defect itself, but in its influence on energy consumption and damage to the environment.

These electric drives use electric motors "Morley" GM66 400/800: rated power, $500 \mathrm{~kW}$; voltage, $1.14 \mathrm{kV}$; nominal power factor, $\cos \varphi=0.87$; speed, $1493 \mathrm{rpm}$.

The vibration spectrum after maintenance is shown in Fig. 2. At the same time, the overall level of vibration decreased three-fold, although some imbalance remained. 


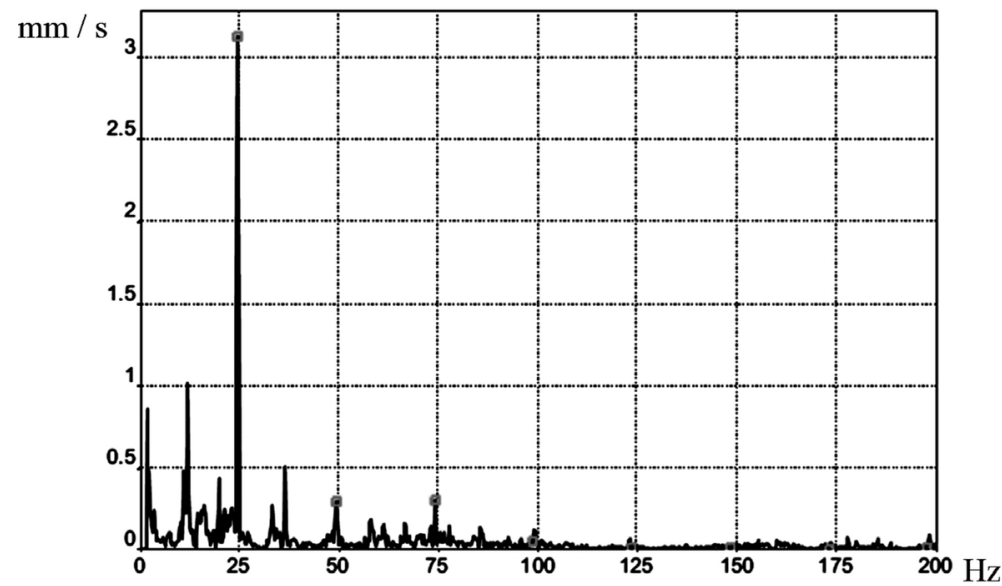

Fig. 2. Spectrum vibrodiagnostics drive after the Maintenance.

\section{Results and discussion}

To estimate the energy consumption of the drive motor, the power $(\mathrm{kW})$ was calculated, before and after the maintenance of the drive:

$$
\begin{aligned}
P_{1} & =1.73 \cdot U \cdot I_{1} \cdot \cos \varphi, \mathrm{kW} \\
P_{2} & =1.73 \cdot U \cdot I_{2} \cdot \cos \varphi, \mathrm{kW}
\end{aligned}
$$

Where $P_{1}, I_{1}$ - power $(\mathrm{kW})$ and current (A) of the electric motor corresponding to the state of the battle of the shaft, before the maintenance; $P_{2}, I_{2}$ - power $(\mathrm{kW})$ and current $(\mathrm{A})$, electric motor corresponding to the combat state after maintenance; $\cos \varphi$ - the nominal value of the motor power factor; $U$-rated mains voltage $(\mathrm{kV})$.

$$
\begin{gathered}
P_{1}=1.73 \cdot 1.14 \cdot 198.00 \cdot 0.87=340.1 \mathrm{~kW} \\
P_{2}=1.73 \cdot 1.14 \cdot 183.70 \cdot 0.87=315.6 \mathrm{~kW}
\end{gathered}
$$

To determine the currents, the data of the work of the conveyor drive motors received from the ACS 800 frequency inverters over a period of one shift (mean current per shift, with the same torque and speed assignments) was used.

Electricity losses $(\mathrm{kW} \cdot \mathrm{h})$, caused by the weakening of the reactive traction of the drive, are determined by the formula:

$$
\Delta W=\left(P_{2}-P_{1}\right) \cdot n, \mathrm{~kW} \cdot \mathrm{h}
$$

Where $n-$ is the number of operating hours of the drive per month, hour.

$$
\Delta W=(340.1-315.6) \cdot 630=15430 \mathrm{~kW} \cdot \mathrm{h}
$$

To compensate for the additional energy consumption, only one engine will have to burn about 6 tons of coal per month. This results in emissions of over 21 tons of carbon dioxide into the atmosphere. This approximate calculation does not take into account the additional costs of transporting additional coal to power plants.

In addition to vibration diagnostics, the possibility of thermal monitoring can be used to estimate energy losses, and, accordingly, the environmental load on the environment. 
The thermal control of roller bearings and other conveyor elements with the help of infrared thermography allows more accurate installation of defective components. For example, to detect local overheating of one bearing, malfunction of the cooling system, defects in the lubrication system. The power used to overcome friction in the bearing [5].

$$
P_{\text {friction }}=M_{\text {friction }} \cdot \omega, \mathrm{W}
$$

Where $M_{\text {friction }}$ - is the frictional moment in the bearing $(\mathrm{N} \cdot \mathrm{m}) ; \omega$ - angular velocity of the bearing $(\mathrm{rad} / \mathrm{s})$.

Friction in rolling bearings is a complex physical process caused by the contact and the General deformations Caprica-related bodies, macro - and microgeometry of a rolling surface, the grease, etc. by Calculating the frictional moment in the bearing 180306 roller $\varnothing 159 \times 600$ mounted on a conveyor belt 3 LL1600 technical capacity of $3,500 \mathrm{t} / \mathrm{h}$ and belt speed of $4 \mathrm{~m} / \mathrm{s}$ has received $M$ friction $=6.8 \mathrm{~N} \cdot \mathrm{m}$.

Angular speed of the roller bearing will be:

$$
\omega=2 \cdot v / D_{p}=2 \cdot 4 / 0.159=50.3 \mathrm{rad} / \mathrm{s}
$$

Bearing features deep groove ball 180306 :

- The inside diameter $d=30 \mathrm{~mm}$.

- Outside diameter $D=72 \mathrm{~mm}$.

- The diameter of the rolling elements $D_{w}=12.3 \mathrm{~mm}$.

- Number of rolling elements -8 .

- Static load rating $C=15100 \mathrm{~N}$.

Calculate the power consumed for heating the roller in the working roller bearing without defects:

$$
P_{\text {friction }}=M_{\text {friction }} \cdot \omega=6.8 \cdot 50.3=342 \mathrm{~W}
$$

The specified heat output, resulted in heating the body bearing-Nika roller exceeding the ambient temperature by $0,8 \div 1,0$ Degrees (see Fig. 3 a). In Fig. 3, 4 shows the thermograms roller belt conveyor.

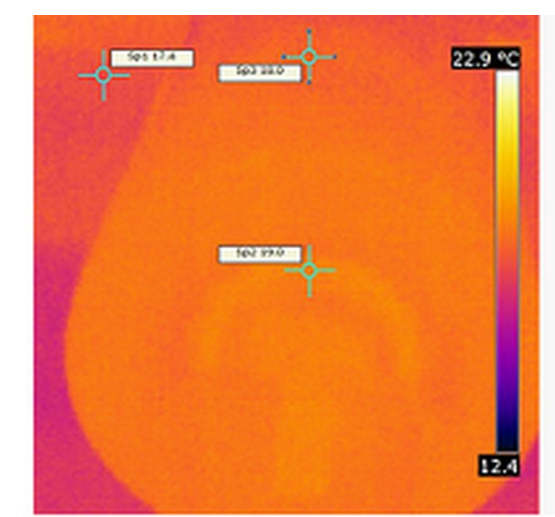

a)

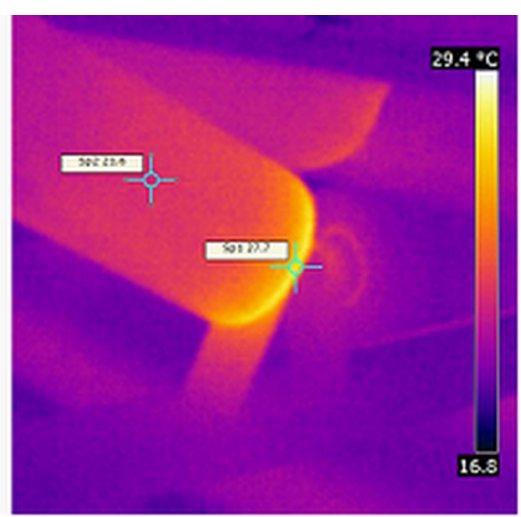

b)

Fig. 3. The thermograms working rollers: a) defect-free; b) - with slight defect.

After was built the dependence of the temperature of the roller surface from heat loss (Fig. 5). 


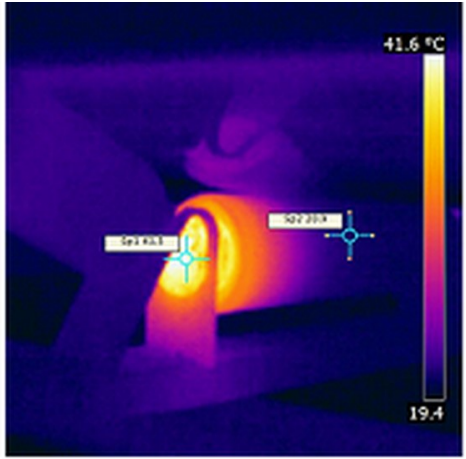

a)

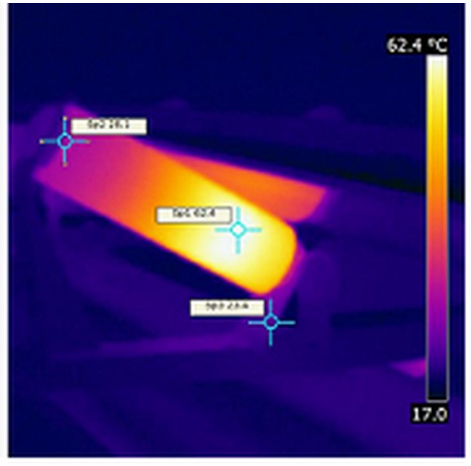

b)

Fig. 4. The thermograms of the defective rollers: a) temperature anomaly zones $C$; b) temperature anomaly zone $D$.

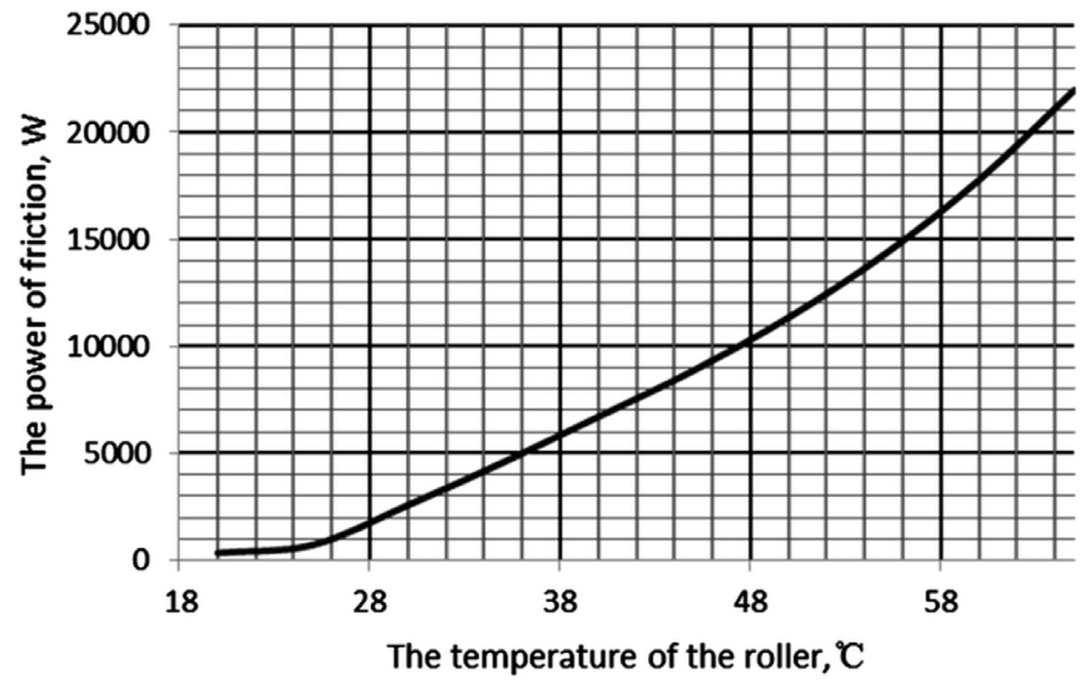

Fig. 5. The dependence of the power of friction from roller temperature.

Analyzing losses on non-productive friction, can make the that, for example, for heating the outer surface of the roller 48 degrees Celsius, you need to spend about $10 \mathrm{~kW}$ (see Fig. 5).

Belt conveyor type 3LL1600 rollers 420 are installed at every 100 meters of pipeline, survey results show the temperature anomalies at $10 \div 15{ }^{\circ} \mathrm{C}$ for $5 \div 10 \%$ of the rollers. Take the averages and calculate power loss for a pipeline length of $1000 \mathrm{~m}$. Get the following value for:

$$
\triangle P=4200 \cdot 0.072 .5=735 \mathrm{~kW}
$$

This capacity exceeds the capacity of the drive motor by 1.5 times. Of the four drive motors, one certainly consumes energy for the rotation of the roller with worngovernmental bearings. Like the example with the vibrodiagnostics calculate energy losses for the month by the formula (5):

$$
\Delta W=\left(P_{2}-P_{1}\right) \cdot n=735 \cdot 630=463050 \mathrm{kWh}
$$


It is about 175 tons of additional coal for electricity generation leads to emissions of more than 615 tons of carbon dioxide per month.

\section{Conclusions}

Thus, periodic monitoring of technical condition of mining equipment, and adequate maintenance significantly reduces the environmental burden on the environment.

\section{References}

1. Environmental and industrial safety at development of useful mineral deposits of States - participants of the CIS. (Mining, Moscow, 2014)

2. E. M. Tseytlin, Theses of the report of VII Krakov Conference of young scientists. AGH University of Science and Technology, 1, 809 (2012)

3. ISO 10816-1, Mechanical vibration - Evaluation of machine vibration by measurements on non-rotating parts (Rosstandart, Moscow, 2000)

4. E. G. Kuzin, B. L. Gerike, Y. V. Drozdenko, M. G. Lupiy, N. V. Grigoryeva, IOP Conf. Series: Materials Science and Engineering, 253, 012013 (2017)

5. B. L. Gerike, A. P. Filatov, P. B. Gerike, V. I. Klishin, Journal of Mining Science, 42(6), 610-616 (2006)

6. A.A. Khoreshok, Ugol', 7, 10-12 (2002)

7. Guang-fu Bin, Xue-jun Li, Balbir S. Dhillon, Zhen-yu Huang, Deng-ta Guo. Journal of Coal Science and Engineering, 16:1, 108 (2010)

8. A. L. Heyes, J. P. Feist, X. Chen, Z. Mutasim, J. R, Nicholls, Journal of Engineering for Gas Turbines and Power, 130 :6, 1 (2008)

9. Li X J, Qiu W L, Chu F L, Chinese Journal of Scientific Instrument, 30 :1, 126 (2009)

10. S. Landelma, E. Juuso, Insight, 49 :12, 719 (2007)

11. X. Z. Wang. New technology of coal mine safety (China Coal Industry Publishing House, Beijing, 2003)

12. B, Orchard, World Pumps, 495, 20 (2007)

13. S. Landelma, E. Juuso, Insight, 49 :12, 719 (2007)

14. P. Konar, P. Chattopadhyay, (SVMs). Appl. Soft Comput. 11, 4203 (2011) 